\title{
LA SIGNIFICACIÓN DE LAS REALES ORDENANZAS EN EL CONTEXTO DE LA REFORMA MILITAR
}

\author{
GUSTAVO SUÁREZ PERTIERRA \\ Catedrático de Derecho Eclesiástico del Estado \\ UNED
}




\section{SUMARIO}

1. El proceso de revisión de las antiguas Ordenanzas. 2. Contenido, naturaLeza e innovación en las Reales Ordenanzas de 1978. 3. La transición política

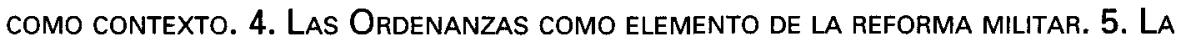
significación de las Reales Ordenanzas. 6. Conclusión. 


\section{LA SIGNIFICACIÓN DE LAS REALES ORDENANZAS EN EL CONTEXTO DE LA REFORMA MILITAR 1}

POR

GUSTAVO SUÁREZ PERTIERRA

\section{EL PROCESO DE REVISIÓN DE LAS ANTIGUAS ORDENANZAS}

El 31 de octubre de 1977, una selecta comisión de oficiales de los tres ejércitos recibía el encargo de elaborar unas nuevas ordenanzas para las fuerzas armadas españolas. Lo había decidido así durante el verano la Junta de Defensa Nacional por inspiración del Teniente General GUTIÉRREZ MELLADO, a la sazón Vicepresidente del Gobierno, que instruye en esta línea a la Junta de Jefes de Estado Mayor mediante una Directiva fechada en el mes de septiembre².

Se trataba de sustituir las viejas Ordenanzas de S.M. para el Régimen, Disciplina, Subordinación y Servicio de sus Exércitos, promulgadas por Carlos III en 1768 (y también las Ordenanzas de Fernando VI

1 Constituye este texto la elaboración de la ponencia presentada en las Jornadas académicas Veinte años de Reales Ordenanzas organizadas por el Instituto Gutiérrez Mellado de la UNED en noviembre de 1998.

2 Es de utilidad para el manejo de los datos del proceso, así como para el conocimiento de los problemas que se plantearon a la Comisión, el escrito de R. SALAS LARRAZÁBAL, secretario de la misma, titulado Las Reales Ordenanzas, en Historia social de las Fuerzas Armadas, dir. M. Hernández Sánchez-Barba y M. Alonso Baquer, ed. Alhambra, Madrid, 1986, VIII, págs. 113 ss. 
para el gobierno militar, político y económico de su Armada Naval, de 1748 , y las Ordenanzas sobre la gobernación militar y marinera de la Armada promulgadas por Carlos IV en 1793), vigentes hasta entonces, pero sólo residualmente, por unas nuevas normas de comportamiento militar adaptadas a la uprofunda transformación política y socioeconómica" de España y a la "ratificación por parte española del Pacto Internacional de Derechos Humanos»3.

El empeño no era nuevo. Aún cuatro años antes de estas fechas, la Armada había creado una Comisión de Ordenanzas Generales, en tanto que el Ejército de Tierra, poco más tarde, constituyó su propia Comisión revisora de la normativa de moral militar. Ambos órganos se transformaron en una Comisión interejércitos cuando se institucionalizó la Junta de Jefes de Estado Mayor ${ }^{4}$.

Pero, ciertamente, la entrada en crisis de las viejas Ordenanzas databa de mucho tiempo atrás. Si, al decir de ALMIRANTE, el sistema de ordenanza no surge hasta el siglo XVI, pues antes no existían ejércitos permanentes 5 , las Ordenanzas de 1768 estaban ampliamente cuestionadas por anacrónicas tan sólo un siglo más tarde ${ }^{6}$. Aunque siempre fueron muy reputadas como un compendio de todo el saber militar del momento, ya sobre las funciones de los distintos empleos, la táctica, los deberes militares, las cuestiones administrativas o las leyes penales, la esperable falta de adaptación a tiempos tan cambiantes provocó su obsolescencia temprana.

El encargo de Gutiérrez Mellado pretendía que se siguiera en lo posible el esquema de las anteriores Ordenanzas y aquellos de sus supuestos que mantuvieran vigencia para constituirse en norma de conducta permanente. Debían incluir los deberes, obligaciones, derechos y normas de comportamiento de todo militar y excluir, no obstante,

3 Vid. Directiva del Teniente General Gutiérrez Mellado, Texto en R. Salas LARRAZÁbal: Las Reales Ordenanzas, cit., págs.121-122.

4 Ibid., págs. 116-119.

5 Vid. J. Almirante: Diccionario militar, ed. del Ministerio de Defensa, Madrid, 1989, t. II, Voz Ordenanza, pág. 797. Defiende Almirante que el germen del sistema debe situarse en el Discurso sobre la forma de reducir la Disciplina Militar a mejor $y$ antiguo estado, publicado por SANCHO DE LONDOÑo en 1594. También puede verse en edición del Ministerio de Defensa, Madrid, 1992.

6 Voz Ordenanza, cit., pág. 803. AlmiRANTE considera las Ordenanzas un "venerable monumento", que recibe su primer conato de reforma ya en 1811. Para el proceso de elaboración de las Ordenanzas y su evolución, vid. F. De SaLAs López: Ordenanzas militares en España e Hispanoamérica, Mapfre, Madrid, 1992, especialmente págs. 53 ss. 
«aquellos aspectos que por estar sujetos a posibles variaciones reglamentarias [...] o referirse a cuestiones administrativas, puedan sufrir transformaciones debidas a la incidencia de los nuevos medios o técnicas que puedan ir apareciendos ${ }^{7}$.

La Comisión comienza rápidamente sus estudios, pues dispone de poco tiempo. Pronto tiene redactado un anteproyecto que, después de su aprobación por las instancias superiores y de la correspondiente tramitación parlamentaria, el 28 de diciembre de 1978 se promulga finalmente por medio de una Ley que aprueba las Reales Ordenanzas para las Fuerzas Armadas 8.

Desde entonces han pasado veinte años. Las Reales Ordenanzas recibieron el correspondiente desarrollo directo en aquellos aspectos que afectan de una manera especial a cada ejército ${ }^{9}$ tratando de ofrecer a sus miembros concretas pautas de actuación. Pero, sobre todo, significaron el inicio de un camino por el que había de discurrir la evolución experimentada por las fuerzas armadas españolas en los años siguientes hasta la actualidad.

\section{CONTENIDO, NATURALEZA E INNOVACIÓN EN LAS REALES ORDENANZAS DE 1978}

Las Reales Ordenanzas se autodefinen como "la regla moral de la Institución Militar y el marco que define las obligaciones y derechos de sus miembros" (art. $1 .^{\circ}$ ). Sin perjuicio del problematismo que bajo diferentes aspectos encierra la definición, es muy claro lo que las Ordenanzas pretenden ser: una especie de marco ético de actuación de los miembros de las Fuerzas Armadas.

No sorprende, desde esta perspectiva, la dificultad que algunos encuentran para considerarlas como una verdadera norma juridica ${ }^{10} \mathrm{ni}$

7 Vid. Directiva, fuente cit., pág. 122.

8 Ley 85/1978, de 28 de diciembre, de Reales Ordenanzas para las Fuerzas Armadas (BOE de 12 de enero de 1979). Su texto puede verse en Legislación sobre Defensa Nacional, edición de G. Suárez Pertierra, Tecnos, Madrid, 1994, 2.a ed.

9 Real Decreto 2945/1983, de 9 de noviembre, por el que se aprueban las Reales Ordenanzas del Ejército de Tierra (BOE de 29 de noviembre). Real Decreto 494/1984, de 22 de febrero, por el que se aprueban las Reales Ordenanzas del Ejército del Aire (BOE de 12 de marzo). Real Decreto1024/1984, de 23 de mayo, por el que se aprueban las Reales Ordenanzas de la Armada (BOE de 30 de mayo).

10 J. FERnÁndez López, muy crítico con las Reales Ordenanzas, pone en cuestión su naturaleza jurídica y especialmente su rango legal. Vid. El Rey y otros mili- 
tampoco la tendencia a situarlas en un plano moral más propio de los praeambula del Derecho. Si son un conjunto de normas éticas de comportamiento, bien pudieran constituir más un catálogo orientador de principios que un auténtico código positivo11, especialmente en algunos de sus aspectos que, como el Título II, no señalan obligaciones sino deberes ${ }^{12}$.

En cuanto a su contenido, el Tratado Primero incorpora bajo la rúbrica "De la Institución Militar" los aspectos relativos a la naturaleza de las fuerzas armadas, su ubicación en el conjunto de las instituciones del Estado, sus misiones y el modo de ejercerlas y las características que mejor las definen. El Título II, "Del militar", recoge los aspectos relativos al comportamiento de los componentes de los ejércitos con base en un personalismo que impregna todo el contenido de las Ordenanzas y que supone uno de los criterios que incorpora novedosamente el sistema de 1978 y que mejor contribuyen a definirlo ${ }^{13}$.

El Tratado segundo se refiere a las "Ordenes particulares" desde una doble perspectiva: los niveles de la jerarquía militar y las funciones militares. Lo verdaderamente innovador es lo segundo, que distribuye en seis grandes campos las funciones del militar: mando, asesoramiento y apoyo, combate, instrucción, adiestramiento y enseñanza, trabajo técnico y administración y logística. La amplitud con que esta perspectiva se introduce en las Ordenanzas lleva a considerar el elemento de la funcionalidad como la segunda característica principal del

tares. Los militares en el cambio de régimen político en España (1969-1982), Trotta, Madrid, 1998, pág. 139.

11 Así, C. Ollero: Constitución y Reales Ordenanzas, en Primeras Jornadas Fuerzas Armadas-Universidad, Madrid, 1982, pág. 226, cit. por F. Fernández Segado: Fuerzas Armadas-sociedad:del mutuo aislamiento a la progresiva integración, en Revista Española de Investigaciones Sociológicas(REIS), 36 (1986)71(169). A. GUAITA sostiene que no son propiamente una ley, pues su contenido no es el propio de los preceptos jurídicos. Vid. Los derechos fundamentales de los militares, en Jornadas sobre el Título Preliminar de la Constitución, Ministerio de Justicia, Madrid, 1988, vol. IV, págs. 2572-2573.

12 Al decir de R. Salas LarRazábal, "no constituye una norma jurídica de Derecho positivo que imponga una concreta manera de actuar con receta infalible para resolver todas las situaciones posibles y bajo la amenaza de una específica sanción a los contraventores, sino algo más profundo: un conjunto de principios éticos que deben incorporarse a las conciencias para que desde ellas actúen imperativamente», op. cit., pág. 134 .

13 F. Laguna Sanouirico considera que el "humanismo" es uno de los criterios que aportan un nuevo enfoque a las Ordenanzas de 1978. Vid. F. DE SALAS LÓPEZ y F. Laguna SANQUIRICO: Las Reales Ordenanzas en el momento actual de la sociedad española, en REIS 36 (1986) 120-122. 
nuevo sistema ${ }^{14}$. La innovación no es tanta, sin embargo, que evite el tratamiento de la jerarquía de empleos militares. Es cierto, no obstante, que pierde peso en relación con la perspectiva funcional indicada $y$ que, incluso aquí, el tratamiento de los niveles jerárquicos, en contra de la tradición, está considerado en grandes bloques (soldado, centinela, suboficial, oficial y oficial general).

Las Reales Ordenanzas finalizan con un Tratado Tercero dedicado a "Deberes y derechos". A la inclusión de esta perspectiva, incluso con el orden formal atribuido a las dos categorías, daba pié la tradición. Mas no es esta la razón de fondo. Una de las razones, no menor y a la que luego se aludirá más detenidamente, para la decisión temprana de redactar una nueva ordenanza en la transición es salir al paso de un movimiento reivindicativo sobre la elaboración de una tabla de derechos y deberes del militar incluidos en una especie de estatuto ${ }^{15}$ según el modelo de función militar francés ${ }^{16}$. De ahí que las Ordenanzas contengan un listado pormenorizado de derechos y deberes del militar, políticos y de naturaleza propiamente militar, en amalgama con lo que el Titulo VI llama "deberes y derechos del militar de carrera", que no es sino un conjunto de preceptos acerca de las vicisitudes profesionales, como empleo, selección, situaciones, formación, destinos, ascensos...

Hasta aquí el contenido esencial de las Reales Ordenanzas de 1978. Quedan fuera de su articulado, con arreglo a las instrucciones recibidas, aquéllas cuestiones concretas que deben derivarse al desarrollo del sistema general ${ }^{17}$, así como un contenido tradicional de la ordenanza militar clásica, la justicia penal, cuya reforma se acomete por otra vía.

Es muy cierto que las Ordenanzas utilizan un lenguaje ambiguo y poco claro. No es, por supuesto, un lenguaje técnico desde la pers-

14 Ibid., págs.127, justificado, según el autor, por el deseo de sintonizar con la organización por sectores laborales de la nueva sociedad industrial.

${ }^{15}$ Así se indica explícitamente en la Directiva del Teniente General GuTiÉRREZ Mellado, fuente cit., pág. 122.

16 Vid. A. Albaladejo Pérez: "El tratado tercero de las Reales Ordenanzas", en Revista de Aeronáutica y Astronáutica, 461 (1979) 399, quien refiere justamente al Consejo de la Función Militar francés lo dispuesto en el art. 205 acerca del "órgano superior encargado de la gestión y coordinación de los asuntos sociales y de personal de las Fuerzas Armadas", que no llegó a ponerse en práctica.

17 Incluso antes de la aprobación de las Reales Ordenanzas, la misma Comisión redactora continúa su trabajo sobre su desarrollo detallado. Vid. F. Laguna Sanouirico: "Segunda parte de las Reales Ordenanzas", en Revista de Aeronáutica y Astronáutica, 461 (1979) 400 ss. 
pectiva jurídica que es propia de una norma legal ${ }^{18}$. Antes bien, el estilo con que en general se expresan va dirigido a resaltar determinados valores como propios, en exclusiva o no, de la organización cuya regulación se pretende. Es así en relación con la clásica tríada de principios que rigen la organización castrense, definidos en el art. 10 pero presentes explícitamente en multitud de lugares paralelos del texto. Lo mismo se puede decir de la utilización del lenguaje, puramente declarativo y en buena medida huero, de la mayor parte de los supuestos contenidos en el Titulo primero. La referencia altamente valorativa a lo simbólico abona la misma conclusión.

Sin perjuicio de que las nuevas Ordenanzas recogen los arquetipos clásicos de las viejas órdenes para oficiales ${ }^{19}$, hay que concluir por la utilización consciente de lo que podría llamarse lenguaje corporativo muy en la línea de las organizaciones fuertemente cohesionadas. Ello está aún especialmente conectado con el concepto de institución en tanto que poder organizado con una idea compartida de la obra a realizar ${ }^{20}$,en el sentido de la autodefinición del art. $1 .^{\circ}$ del propio texto, o en tanto que modelo de organización divergente de la organización civil y que, por serlo, favorece la autonomía de lo militar ${ }^{21}$. Este modelo de lenguaje está tan enraizado en determinadas capas militares que provoca el rechazo a la incorporación de términos que son más propios de aquello que quiere definirse que otros supuestamente más vinculados con el quehacer profesional de la organización militar22.

18 Vid. La reflexión de F. LóPEz RAmón: La caracterización jurídica de las Fuerzas Armadas, Centro de Estudios Constitucionales, Madrid, 1987, pág.321 (27).

19 Así J. L. PITARCH: El honor y el honor militar, Grijalbo, Barcelona, 1984, pág. 57

20 Vid. F. Trillo-Figueroa: "Las Fuerzas Armadas en la Constitución española. Esbozo de una construcción institucional", en Revista de Estudios políticos, 12 (1979) 75.

21 En la tipología de Ch. C. Moskos: "La nueva organización militar: ¿institucional, ocupacional o plural?", en La institución militar en el Estado contemporáneo, comp. R. BAÑón y J. A. Olmeda, Alianza, Madrid, 1985, págs. 140 ss.

22 Valga por todos un ejemplo suficiente. La Ley 17/1989, de 19 de julio, reguladora del régimen del personal militar profesional debe su nombre a la oposición de algunos sectores militares, fundamentalmente representados por quienes en aquel momento componían el Consejo Superior del Ejército de Tierra, a la denominación mucho más adecuada de Ley de la Función Militar, que supuestamente dejaba al margen el componente vocacional de la profesión militar para sustituirlo por una al parecer devaluada relación de dependencia funcionarial. La acogida de esta argumentación por un sector del Parlamento determinó, en aras de un mayor acuerdo, el cambio de nombre en el texto final de la Ley. 
No es, en efecto, un lenguaje técnico el que está contenido en las Reales Ordenanzas. Y así, los mandatos, en los que fundamentalmente consisten las leyes, son muchas veces mandatos que hacen referencia a convicciones morales más que mandatos sobre conductas personales, o lo son sobre acciones poco concretables a los términos jurídicos de exigencia bajo sanción. En ocasiones son curiosos mandatos al legislador (vid. Art. 176) o de imposible cumplimiento, pues dependen de las conductas ajenas (vid. Art. 101).

El apego a la tradición se manifiesta, quizá mejor que en otros campos, en las técnicas que se emplean para aprobar las Reales Ordenanzas.

Repárese en el carácter de la norma: es una ley que aprueba las Reales Ordenanzas para las fuerzas armadas. Sin perjuicio de que esta técnica es posible y correcta ${ }^{23}$, no se trata aquí de una ley que pretenda normar una relación o una situación jurídica o que se superponga a otra disposición general, como pasa con todas las leyes. No se trata de la ley que define el estatuto del militar ni de la ley que determina la naturaleza de los ejércitos y sus funciones.

Es, ciertamente, una ley, pero dispone de un cierto regusto a carta otorgada. Si fuera posible, que no lo es, en nuestro Derecho, pretendería tratarse de una ordenanza clásica sobre el carácter de lo militar y la conducta de los militares concedida por la Corona y aprobada mediante ley. Esta técnica da la medida del anclaje de las Reales Ordenanzas en la historia.

Precisamente el rango de la disposición que había de aprobarlas fue uno de los problemas que se planteó. Parece que Gutiérrez Mellado pensaba en un real decreto que incluía un preámbulo que incluso pudo llegar a constituirse en una alocución real que acompañara al texto aprobado ${ }^{24}$. La insistencia de algún miembro de la comisión redac-

23 La técnica dispositiva de artículo único que aprueba textos jurídicos completos es frecuente en los reglamentos y más extraña en normas jurídicas. Hay, en efecto, ejemplos de leyes así aprobadas; nótese, sin embargo, que todos responden a razones de carácter técnico que no son de aplicación pacífica al caso de las Ordenanzas: leyes que aprueban textos refundidos, leyes orgánicas del art. 93 de la Constitución sobre autorización al ejecutivo, leyes que aprueban acuerdos del Estado con determinadas organizaciones, como las del art. $7 .^{\circ}$ de la Ley orgánica de Libertad religiosa o leyes que aprobaron algunos acuerdos sociales.

24 Es noticia de R. Salas Larrazábal, Las Reales Ordenanzas, cit., pág. 129. Así interpreto su expresión: “...se pensó en que fueran promulgadas por el Rey en su condición de jefe supremo de las fuerzas armadas...y refrendadas por el Ministro de Defensa previo conocimiento y aprobación del Consejo de Ministros". 
tora introdujo la duda, que fue resuelta en favor del rango legal por el propio Presidente del Gobierno25.

Siendo todo esto verdad, se equivocaría quien pensara que las Ordenanzas no incluyen elementos innovadores. Antes bien, son nuevas algunas de las soluciones que ofrecen, precisamente porque constituyen un intento de acomodación a las nuevas circunstancias de la legalidad de las fuerzas armadas.

Y así, constituye una innovación la definición de lo militar a través del tratamiento del militar, siguiendo el criterio personalista que se ha indicado más arriba. Pero también lo son, y mucho, cuando introducen en el art. 9. Ia referencia, adelantada a los tiempos, a las misiones militares de colaboración "para mantener la paz y la seguridad internacionales", que tantas posibilidades han ofrecido en el futuro mediante la utilización de los ejércitos como instrumento de la política internacional del Estado. También es completamente nuevo, obviamente, el conjunto de referencias a la Constitución que las Reales Ordenanzas introducen. El art. $11 .^{\circ}$, en un planteamiento por lo demás extraordinariamente sugerente, considera el acatamiento a la Constitución, "al que la Institución Militar está subordinada", como la "expresión colectiva" de la disciplina, en tanto que el art. $26 .^{\circ}$ establece que "todo militar deberá conocer y cumplir exactamente las obligaciones contenidas en la Constitución».

Con todo, es pensamiento común en la doctrina que la innovación más profunda viene dada por el tratamiento otorgado a una cuestión de primer orden en la política militar: la obediencia debida. Este instituto, considerado como eximente en el Derecho penal común y también en el Código penal militar de 1945 (aunque, en el caso del Derecho militar, con remisión a su calificación por parte de los tribunales), recibe en las modernas Ordenanzas un tratamiento especial.

La fórmula está contenida en el artículo 34: "Cuando las órdenes entrañen la ejecución de actos que manifiestamente sean contrarios a las leyes y usos de la guerra o constituyan delito, en particular contra la Constitución, ningún militar estará obligado a obedecerlas; en todo caso asumirá la grave responsabilidad de su acción u omisión». La in-

25 Era la posición, al parecer minoritaria, del secretario de la comisión. Ibid., págs. 130-131. J. Fernández LóPEZ atribuye la decisión final, aunque con menos seguridad, al propio Teniente general GuTIÉRREZ MELLADo, vid. El Rey y otros militares..., cit., pág. 139. 
terdicción de las órdenes contrarias a la ley se incluye en un supuesto correlativo ${ }^{26}$.

Esta regulación pasa directamente a la ley orgánica 9/1980 de reforma del Código de justicia militar ${ }^{27}$, no sin que se hubieran alzado voces denunciando el peligro que para la disciplina militar supondría la puesta en cuestión de las órdenes del superior ${ }^{28}$.El Código penal militar reformado de $1985^{29}$ no hace sino consolidar un sistema especial con respecto del Derecho penal común que ya habían diseñado las Ordenanzas y recogido la primera reforma de 1980. De ahí que se haya tildado de excesivo mimetismo en relación con las Ordenanzas, también en los errores técnicos ${ }^{30}$.

La figura de la obediencia debida siempre ha planteado problemas dogmáticos ${ }^{31}$. Aunque tradicionalmente incluida por nuestros códigos penales entre el elenco de circunstancias eximentes, ha desaparecido del que contiene el art. 20 del nuevo Código penal de 1995. Comunmente se acepta que esto responde a que la ley ha entendido que no se trata más que de un supuesto específico de la circunstancia de "cumplimiento de un deber» que acoge el n. $7 .^{\circ}$ del propio art. 20, puesto que depende de un deber previo cuyo cumplimiento se expresaba en términos de acatamiento u obediencia. El Derecho militar que parte de las Ordenanzas sigue, sin embargo, vigente y tuvo en su momento importante aplicación en el juicio a los implicados en los sucesos del asalto al Congreso de los Diputados el 23 de febrero de $1981^{32}$.

26 Art. 84: "Todo mando tiene el deber de exigir obediencia a sus subordinados y el derecho a que se respete su autoridad, pero no podrá ordenar actos contrarios a las leyes y usos de la guerra o que constituyan delito".

27 Ley orgánica 9/1980, de 6 de noviembre, de Reforma del Código de Justaicia militar (BOE de 21 de noviembre).

28 Vid. J. Valenciano AlmoYna: La reforma del Código de Justicia militar. Comentarios a la Ley orgánica 9/1980, Madrid, 1980, pág. 96 ss., quien califica de uextraño", además de "novísimo", el precepto paralelo incluido por las Reales Ordenanzas.

29 Aprobado por Ley orgánica 13/1985, de 9 de diciembre (BOE de 11 de diciembre), texto en Legislación sobre Defensa nacional, parágr. 18.

30 Vid. E. CALDERón SUSIN: Circunstancias eximentes, atenuantes y agravantes (artículos 21 y 22), en Comentarios al Código penal militar, coord. R. BLECUA FrAga y J. L. Rodriguez-Villasante y Prieto, Civitas, Madrid, 1988, págs. 416-417.

31 Vid. L. Morillas Cueva: La obediencia debida. Aspectos legales y político criminales, Civitas, Madrid, 1984.

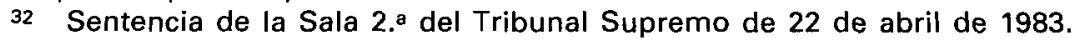
RepJur vol. I (1983) 2300. 


\section{LA TRANSICIÓN POLITICA COMO CONTEXTO}

Es precisamente el afán innovador el aspecto más valioso de las nuevas Ordenanzas. Su verdadero alcance solo puede entenderse si se sitúan convenientemente en el contexto histórico.

El papel político de los ejércitos en los últimos tiempos del régimen franquista es más reducido de lo que a primera vista pudiera pensarse. Aunque su influencia persistía, su participación en los centros de decisión esenciales del régimen no se producía propiamente como tales ejércitos, es decir, en tanto que institución ${ }^{33}$. Las fuerzas armadas cumplen la función de garantes del sistema político, que por esta vía resulta un sistema militarizado ${ }^{34}$, pero la militarización se concreta fundamentalmente en dos aspectos, ciertamente claves, de la acción del régimen: el orden público y la extensión de la jurisdicción militar hacia los delitos políticos, aún no cometidos por militares ${ }^{35}$. Aunque la presencia en las instituciones de personalidades militares sigue siendo numerosa y significativa, lo cierto es que el régimen de Franco ya había desarrollado a estas alturas un complejo sistema de legitimaciones que le permitían no tener que descansar únicamente en el soporte militar ${ }^{36}$.

Con el fin de la dictadura España se encuentra con unas fuerzas armadas sobredimensionadas y aisladas internacionalmente, cuyos mandos superiores proceden de la guerra civil, infradotadas en medios materiales y carentes de moderna tecnología. Si bien no es cierto que

33 Es la tesis mantenida por un amplio sector de la doctrina. Así, F. Agüero: Militares, civiles y democracia. La España postfranquista en perspectiva.comparada, Alianza ed., Madrid, 1995, pág.88.

34 Vid. R. L. BLANCo VAldés: La ordenación constitucional de la Defensa, Tecnos, Madrid, 1988 , págs. $54-55$.

35 Además de los estudios citados en las dos notas anteriores, vid. M. BALLвÉ: Orden público y militarismo en la España constitucional (1812-1983), Alianza, Madrid, 1983, especialmente págs. 397 ss. También R. Bañón Martínez y J. A. OlmeDA GÓmEz: "Las fuerzas armadas en España. Institucionalización y proceso de cambio", en La institución militar en el Estado contemporáneo, cit., págs. 270 ss.

36 Vid. F. Rodrigo: "El papel de las fuerzas armadas españolas durante la transición política: algunas hipótesis básicas", en Revista Internacional de Sociología, 43 (1985) 357. El franquismo, a diferencia de los sistemas totalitarios, resultó "biodegradable", es decir, generó dentro de sí mismo procesos de autorreforma que acabaron transformando inevitablemente el régimen en una democracia. Es conclusión de M. PASTOR: "Las postrimerías del franquismo", en Transición política y consolidación democrática. España (1975-1986), comp. R. CotARELo, CIS, Madrid, 1992, pág. 46. 
los presupuestos anuales no allegaran recursos cuantiosos para el sostenimiento de los ejércitos, no lo es menos que los esfuerzos financieros se diluyen en la desproporción del personal ${ }^{37}$.

En este cuadro son permanentes los problemas que los sucesivos acontecimientos políticos de la transición provocan en las fuerzas armadas. Son conflictos derivados de la construcción del incipiente Estado de Derecho, la puesta en marcha de la nueva organización territorial o la introducción de las libertades ${ }^{38}$. Provocan crisis más o menos contínuas -en las que la reacción del Gobierno es frecuentemente débil o desafortunada ${ }^{39}$ - que funcionan como catalizadores de un germen de indisciplina que eclosiona finalmente en el esperpento del asalto al Congreso de los Diputados el 23 de febrero de $1981^{40}$.

El momento de la transición no es uniforme; pueden distinguirse sucesivas etapas ${ }^{41}$. Conviene tener presente, sin embargo, a efectos de una interpretación correcta del contexto de la transición, una idea fundamental aplicable al conjunto de período: la intervención militar que se produce en la vida pública durante el franquismo, con los matices antes indicados, no se produce durante la transición. Tanto es asi que se han citado solamente dos únicos ejemplos de presión directa de los militares sobre el poder político. Uno de ellos consistió en la actuación de algunos generales, por cierto que junto con GUTIÉRREZ MELLADO42, dirigida a impedir que el proyecto de ley de amnistía preparado en 1977 compren-

37 Así lo ha demostrado J. A. Olmeda Gómez: Las Fuerzas Armadas en el Estado Franquista, El Arquero, Madrid, 1988, especialmente págs. 186 ss.

38 Vid. G. SuÁrez Pertierra: «La Administración militar a lo largo de los veinte años de vigencia de la Constitución", en Administraciones públicas y Constitución. Reflexiones sobre el XX aniversario de la Constitución española de 1978, ed. E. Álvarez Conde, INAP, Madrid, 1998, pág. 596.

39 En opinión de J. FeRnÁNDEZ LóPEZ: El Rey $y$ otros militares..., cit., págs. $118 \mathrm{ss}$.

40 La noticia de los numerosos episodios concretos puede verse en ibid. También C. FERnÁNDEZ: Los militares en la transición política, Argos Vergara, BarceIona, 1982.

41 N. Serra realiza una periodificación que distingue dos grandes etapas en el proceso de transformación de las fuerzas armadas españolas: una etapa de transición (1976-1982) y una etapa de consolidación (1982-1989). Dentro de la primera son separables la etapa de Gutiérrez Mellado como Ministro (1976-marzo de 1979), de Rodríguez Sahagún (1979-febrero de 1981) y de Calvo Sotelo como Presidente y Oliart como Ministro (1981-diciembre de 1982).Vid. "La consolidación de la democracia en España. La reforma militar», conferencia pronunciada en la London School of Economics el 26 de enero de 1999, pro manuscripto.

42 Aunque el Teniente General había expresado antes, "de palabra y por escrito", la necesidad de actuar cuidadosamente en este caso, pues la campaña de 
diera también a los militares de la UMD que habian sido expulsados del ejército en 1975, como así fue. El otro ejemplo lo constituyó la reacción por la legalización del partido comunista ${ }^{43}$.

Si esto es así al comienzo de la transición, sin embargo, los sucesos externos, entre los que no fue menor el terrorismo practicado sobre los miembros de las fuerzas armadas ${ }^{44}$, junto con las reacciones a veces temerosas por parte de las autoridades, provocaron un afianzamiento de las posiciones intransigentes dentro del ejército ${ }^{45}$. Los procesos de involución fueron cuajando progresivamente hasta el intento de golpe de estado de 1981, si bien el propio planteamiento del golpe, la actuación de S.M. el Rey y la de los implicados durante el juicio de los hechos acabaron constituyendo garantía de fracaso para intentos futuros ${ }^{46}$.

En el contexto que acaba de explicarse no resulta posible desconocer la entidad de la reforma militar que emprenden ADOLFO SUÁREZ y MANUEL GUTIÉRREZ MELLADO, dentro de la que tienen su lugar las nuevas Ordenanzas. A pesar de que suelen ser consideradas de pasada por la doctrina que analiza el conjunto de medidas que concretaron la reforma, constituyeron un hito importante que ocasionó reservas y reticencias dentro de las fuerzas armadas 47 y que atrajo la crítica de muchos desde perspectivas diferenciadas ${ }^{48}$.

desprestigio que sufrian estos militares era una barbaridad y magnificaba el escándalo. Noticia tomada de F. PUeLL DE LA VILLA: Gutierrez Mellado. Un militar del siglo XX (1912-1995), Biblioteca Nueva, Madrid, 1997, pág. 175.

43 Vid. F. Agüero: Militares, civiles y democracia..., cit., págs. 157 ss.

44 Hasta el extremo de que el Gobierno siempre pretendió aislar el fenómeno del terrorismo de las fuerzas armadas, para impedir su utilización por los militares descontentos. Vid. N. Serra: La consolidación de la democracia en España..., cit. Durante los años 1975 a 1980, en que alcanza su punto culminante, el terrorismo crece de una manera formidable, tanto en número de atentados con resultado mortal cuanto en número de muertes. Vid. sobre el particular F. ReInARES: “Democratización y terrorismo en el caso español", en La transición democrática española, ed. J. F. Tezanos, R. Cotarelo, A. De Blas, Sistema, Madrid, págs. 611 ss.

45 Así lo demuestra F. AgüEro: Militares, civiles y democracia..., cit., pág.259.

46 Así lo considera N. Serra. Vid. La consolidación de la democracia en España..., cit.

47 R. Salas LarRazÁbal cuenta cómo se formaron diversos equipos entre los redactores de las Ordenanzas para ir dando a conocer su contenido en las unidades, que carecían de información sobre el particular. La tarea, dice, "no resultó excesivamente grata para los comisionados". Vid. Las Reales Ordenanzas para las Fuerzas Armadas, cit., pág. 131.

48 Como la del general CANo PORTAL en el diario ultraconservador El Alcázar y la del coronel, ex miembro de la UMD, Otero. Noticias tomadas de C. Fernández: Los militares en la transición política, cit., págs. 305-306. 


\section{LAS ORDENANZAS COMO ELEMENTO DE LA REFORMA MILITAR}

El general GUTIÉRREZ MELLADO diseñó una reforma militar que sirviera de guía a los ejércitos para el paso de la dictadura a la democracia o, lo que es lo mismo, que facilitara la adaptación de las fuerzas armadas al Estado de Derecho.

Estableció para esto un plan ambicioso que tuvo como objetivos fundamentales, en mi criterio, la asignación a las fuerzas armadas de un nuevo papel en la sociedad española y el aseguramiento de la disciplina de sus miembros a través de la profesionalización ${ }^{49}$. Los hitos fundamentales de este plan fueron los siguientes:

\section{1. ${ }^{\circ}$ La organización de la defensa}

La historia no fue sencilla y sí rica en intentos que no tuvieron éxito. El proceso comienza en 1974, cuando un proyecto de Ley Orgánica de la Defensa Nacional, inspirada desde tiempo atrás por el Teniente General DÍEZ ALEGRÍA, se remite a las Cortes. El proyecto pretendía la creación de la Junta de Jefes de Estado Mayor con un Jefe del Alto Estado Mayor al frente que recibía la competencia de la conducción de las operaciones, mientras que el mando sobre las unidades recaía sobre cada uno de los Jefes de Estado Mayor en perjuicio de los ministros de cada departamento, que pasaban a ejercer funciones meramente administrativas ${ }^{50}$.

La oposición de los sectores intransigentes $\gamma$, al fin, el asesinato de CARRERO dan al traste con el proyecto, que el Gobierno retira. Este proyecto fallido marca el inicio de una disociación dialéctica entre los cargos político-administrativos y los cargos técnico-militares en la dirección de la defensa51 que será una constante hasta comienzos de1984.

49 También pueden expresarse de otras maneras, como, por ejemplo, hace M. Mella MÁrouez: acabar con el intervencionismo y constitucionalizar las fuerzas armadas. En "Los grupos de presión en la transición política», en La transición democrática española, cit., pág. 167.

50 F. Agüero: Militares, civiles y democracia..., cit., págs. 213-214.

51 En afirmación de J. LLEIXÁ: Autonomía del ejército y órganos superiores de la defensa en la transición, en REIS, 36 (1986), 106. 
Quizá la medida de más entidad de todo el proceso por las consecuencias que va a desarrollar sea la creación de la Junta de Jefes de Estado Mayor 52 . Sobre la base del Alto Estado Mayor reorganizado en 1976 y después de establecer, a semejanza de la Armada que lo había hecho en 1970, la figura del Jefe de Estado Mayor para los ejércitos de Tierra y Aire ${ }^{53}$, se crea una Junta de Jefes de Estado Mayor con el carácter fundamental de órgano colegiado superior de la cadena de mando militar 54 . La figura procede con toda evidencia del proceso que se había interrumpido en 1974 y constituye una concesión importante a los deseos autonomistas del sector del ejército que pretendía sustraer a las fuerzas armadas de la dirección del Gobierno por medio de su directa vinculación al Estado a través del Rey55.

Y así, cuando se crea el Ministerio de Defensa fusionando los tres ministerios militares 56 , dando respuesta a un tan elemental como necesario principio de coordinación ${ }^{57}$, la dirección política de la defensa queda inevitablemente escindida en dos ramas, los ejércitos permanecen fuera del nuevo órgano integrado ${ }^{58}$ y comienzan a aparecer un conjunto de problemas funcionales que dificultan y hasta impiden la dirección de las políticas sectoriales en las fuerzas armadas y que no tienen solución hasta muy entrada la década siguiente 59 .

La decisión de crear un solo Ministerio es, ciertamente, valiente $\gamma$ auda $z^{60}$, seguramente de una importancia sustancial para el buen re-

52 Así lo considera, en opinión que comparto, N. Serra: La consolidación de la democracia en España..., cit.

53 Real Decreto 3026/1976, de 23 de diciembre (BOE de 11 de enero de 1977), Real Decreto-ley 9/1977, de 8 de febrero (BOE de 9 de febrero). Ley $9 / 1970$, de 4 de julio (BOE de 7 de julio), Orgánica de la Armada. Su texto en Legislación sobre defensa nacional, cit., parágr. 11.1.

54 Real Decreto-ley 11/1977, de 8 de febrero (BOE de 9 de febrero).

55 Vid. N. SerRa: La consolidación de la democracia en España..., cit.

56 Real Decreto 1558/1977, de 4 de julio (BOE de 5 de julio).

57 Vid. R. L. BLANCO VALDÉS: La ordenación constitucional de la defensa, cit., pág. 85.

58 Como ponen de manifiesto M. Dominguez Berrueta, D. Fernández de Gatta, M. M. Fernando, P. T. Nevado: Constitución, polícía y fuerzas armadas, M. Pons, Madrid, 1977, pág. 42.

59 Véanse las sucesivas publicaciones del Ministerio de Defensa. Memoria de la legislatura, 4 t., Madrid, 1986, 1989, 1993 y 1996, en su apartado «Estructura y consolidación del Departamento".

60 Así lo considera N. Serra: La consolidación de la democracia en España..., cit. 
sultado de la reforma61, pero trae consigo el germen de la debilidad62. Por ello, un órgano que debiera constituirse en pieza fundamental de control no pasa de ser un cauce de mera coordinación de algunos aspectos administrativos de la política militar. De ahí que deba sostenerse que la Junta de Jefes de Estado Mayor, más que preparar el camino para la creación del Ministerio, como sostienen algunos ${ }^{63}$,condiciona propiamente la naturaleza de éste.

Este proceso continúa con la ley sobre funciones de los Organos superiores del Estado en materia de Defensa nacional de 197864, que incorpora los criterios ya apuntados desde 1974. Lo más destacable de este texto es que constituye un nuevo ejemplo -el otro son las propias Ordenanzas- de la curiosa técnica de legislar en paralelo a la elaboración de la Constitución. Ello permite incorporar al texto la referencia constitucional, pero también manifiesta, cuando se produce, la falta de coincidencia con la norma superior. $Y$ así, aunque el texto legal recoge la defensa de la Constitución proveniente del art. $8 .^{\circ}$ entre las misiones de las fuerzas armadas, que no estaba incluida en el proyecto, la insistencia en la idea cadena de mando militar provoca una divergencia en relación con la atribución constitucional al Gobierno de la dirección de la política militar 65 .

Con todo, una vez aprobada la Constitución, cuyo art. $8 .^{\circ}$ prevé la promulgación de una ley que regule las bases de la organización militar, de nuevo se siente la necesidad de elaborar una disposición de carácter general. La ley orgánica de Criterios básicos de la Defensa nacional y de la Organización militar de $1980^{66}$, siendo ya desarrollo de la Constitución, no innova prácticamente en nada el régimen establecido hasta entonces, a pesar del intermedio hito constitucional. Las responsabilidades militares siguen en manos de un órgano colegiado, que es ejecutivo, y de los Jefes de Estado Mayor. Aunque el Gobierno determina la política de defensa y dirige la administración militar, su Presidente tiene funciones muy generales de dirigir y coordinar la acción del

61 F. Puell de la Villa afirma que esta medida era para GutiérRez Mellado la fundamental de su programa. Vid. Gutierrez Mellado. Un militar..., cit., pág. 207.

62 Así, F Agüero: Militares, civiles y democracia..., cit., págs. 252-253.

63 Vid. M. Domínguez Berrueta y otros: Constitución, policía y fuerzas armadas, cit., pág. 36.

64 Ley 83/1978, de 28 de diciembre (BOE de 12 de enero de 1979).

65 Vid. M. Domínguez BerRueta y otros: Constitución, policía y fuerzas armadas, cit., págs. 47-48.

66 Ley orgánica 6/1980, de 1 de julio (BOE de 10 de julio), texto en Legis/ación sobre defensa nacional, cit., parágr. 2.1 
Gobierno, en tanto que el Ministro de Defensa sólo tiene competencias residuales que ejerce por delegación.

Sin duda porque en la fecha permanecen los problemas políticos de la transición, la ley de Criterios básicos de 1980 no aprovecha la regulación constitucional, antes bien, actúa como si no se hubiera producido cambio sustancial alguno en relación con el momento preconstitucional67, derivando a los años sucesivos la reforma de los órganos superiores de la defensa que forzosamente había de llegar.

Por el contrario, la Constitución establece un tratamiento nuevo de los problemas de la defensa. A pesar de las posiciones divergentes acerca del sentido de la ubicación del art. $8 .^{\circ}$ en el Título Preliminar, el juego de este supuesto con el art. $97 .^{\circ}$ del propio texto constitucional o, lo que es lo mismo, el binomio constitucionalización de las misiones de las fuerzas armadas (art. $8^{\circ}$ ) - atribución al Gobierno de la dirección de la administración militar (art. $97 .^{\circ}$ ) no permite mantener la conclusión de que no se produce un cambio sustancial que da al traste con el sistema anterior fundamentado en un cierto grado de autonomía de los ejércitos ${ }^{68}$.

De ahí que en 1984, cuando ya se han superado los problemas y el grado de consolidación democrática es suficiente, sea necesario proceder a la reforma aplazada. Una nueva ley orgánica de Criterios básicos de la defensa nacional y de la Organización militart9 revisa el sistema constituyéndose en el verdadero desarrollo constitucional.

Este es, en efecto, el verdadero desarrollo que esperaba el texto constitucional desde 1978 y no la Ley de Criterios básicos en su redacción de 1980. Por eso no es correcto sostener que hay en 1984 un cambio de criterio con el consiguiente deterioro del espiritu de la Constitución $^{70}$. En ninguna parte del texto constitucional está dicho que haya

67 No es correcto distinguir, por consiguiente, una segunda etapa o modelo en 1980, como hacen M. Domínguez BerRueta y otros: Constitución, polícía y fuerzas armadas, cit., pág. 56.

68 He insistido en la cuestión desde la perspectiva constitucional en Regulación jurídico-constitucional de las fuerzas armadas, en Jornadas de estudio sobre el Título Preliminar de la Constitución, cit., vol. IV, págs. 2361 ss.

69 Ley orgánica $1 / 1984$, de 5 de enero (BOE de 7 de enero), texto en Legislación sobre defensa nacional..., cit., parágr. 2.2.

70 Como propone R. Parada en su "Prólogo" a M. Dominguez Berrueta y otros: Constitución, policia y fuerzas armadas, cit., págs. 10-11. Para este autor, el antimilitarismo socialista pone en marcha una "operación de sordina de la regulación constitucional y de las reformas del Gobierno de la UCD» que consiste, al pa- 
que distinguir entre una línea de mando militar y otra línea de administración o de dirección política; en ningún lugar constitucional se consolida el modelo que sitúa a un órgano colegiado en la cúspide del poder militar en contra de los sistemas conocidos; nada permite afirmar que la Constitución aboga porque la administración civil y la militar tengan distinta naturaleza. Estos planteamientos, por el contrario, fueron cesiones preconstitucionales en el modelo de adecuación de los ejércitos a posiciones que pretendieron condicionar la evolución de la transición política y que no merman en nada el vigor de las reformas posibles que se emprendieron.

La reforma de 1984, finalmente, introdujo un proceso de individualización de las responsabilidades. Las atribuciones de Presidente del Gobierno y Ministro de Defensa, ahora definidas, se combinan con la aparición de la figura del Jefe del estado Mayor de la Defensa, que preside una Junta de Jefes de Estado Mayor que sólo tiene carácter consultivo, como el resto de los órganos colegiados. Las líneas de organización se depuran para integrar a los ejércitos en el Ministerio de Defensa y las estructuras se acomodan preparándose para el cambio de una doctrina de defensa proyectada al exterior 71 .

A partir de aquí, queda establecido un sistema más congruente con la Constitución ${ }^{72}$, que había quedado aplazado por causa de las circunstancias. Puede entenderse que culmina en estos años el proceso de constitucionalización de los ejércitos ${ }^{73}$.

\section{2. ${ }^{\circ} \quad$ La profesionalización}

La idea de profesionalización de los militares es fundamental en el diseño de la reforma. Se refleja desde muy pronto en un conjunto de medidas concretas cuya importancia para la disciplina de los ejércitos

recer, en forzar la Constitución para equiparar administración civil y militar, silenciar la posición del Jefe del Estado como mando supremo de las fuerzas armadas, destinar funcionarios civiles al Ministerio de Defensa, someter los institutos armados al mando de políticos como Roldán (sic) y otras arbitrariedades. Todo esto pasa porque se abandona la tesis institucionalista. Si se escribe esto en 1997, ¿es acaso supérfluo, como algunos pretenden, remachar la idea de que las fuerzas armadas son constitucionalmente parte de la administración?

71 Vid. N. Serra: La consolidación de la democracia en España..., cit. También G. SuÁrez Pertierra: La Administración militar..., cit., págs. 598 ss.

72 En opinión de J. LleIXÁ: Autonomía del ejército y órganos superiores..., cit., pág. 106.

73 Vid. F. AgüERo: Militares, civiles y democracia..., cit., pág. 356. 
no se corresponde a veces con la entidad aparente de aquellas o con el instrumento jurídico requerido para ponerlas en práctica.

GUTIÉRREZ MELLADO promueve diversas actuaciones que inciden en la dedicación profesional. En este sentido, se dictaron normas para la implantación de la jornada continuada, que pretendía acabar con el pluriempleo de los militares, sobre retribuciones y sobre asistencia social (se crea el Instituto Social de las Fuerzas Armadas) y también se establecieron medidas para proceder al rejuvenecimiento de los cuadros de mando ${ }^{74}$.

Lo fundamental, no obstante, fue la promulgación del Real Decreto-ley sobre el ejercicio de actividades políticas y sindicales por parte de los componentes de las fuerzas armadas ${ }^{75}$.

Esta norma prohibe por completo el ejercicio de actividades políticas y sindicales por los militares en situación de actividad. Salvo el ejercicio del derecho de sufragio activo, se prohibe la participación en todas las actividades que tengan que ver con la toma de posición política o sindical. Quedan, así, prohibidas la afiliación, el apoyo y la asistencia a reuniones, la expresión pública de opiniones, el sufragio pasivo $y$ el ejercicio de cargos de designación directa salvo los de administración militar. Para formar parte de candidaturas o para poder ejercer cualesquiera de estas actividades, el militar deberá pasar a la situación de retiro o, en el caso de los generales, a una situación especial que se crea en el propio Real Decreto-ley.

Algunos consideraron entonces excesivamente rigurosa la medida que contenía la norma legal ${ }^{76}$ por cuanto obligaba a prescindir del apoyo de aquellos militares que desde puestos del ejecutivo prestaban sus esfuerzos para ayudar a sacar adelante las reformas. Sin dejar de valorar el concurso de estas personas, la imposibilidad de hacer distinciones entre unos y otros militares parecía más bien aconsejar una medida general que evitara intervenciones políticas, aún encauzadas legalmente, en una circunstancia histórica en que la acción y expresión política y la vida de las unidades no disponía de una frontera clara.

74 Vid. F. Rodrigo: El papel de las fuerzas armadas..., cit., págs. 367-368. También F. PueLL DE LA VILLA: Gutierrez Mellado. Un militar..., cit., págs. 210 ss.

75 Real Decreto-ley 10/1977, de 8 de febrero (BOE de 9 de febrero). Su texto en Legislación sobre Defensa nacional, pargf. 17.1.

76 Véanse los datos y los comentarios de J. Fernández López: El Rey y otros militares..., cit., págs. 103-104. 
El Real Decreto-ley debe interpretarse como una medida de profesionalización en la línea del mantenimiento del principio de disciplina al que la regulación del momento concedió una relevancia extraordinaria77. En la disciplina y en la neutralidad política hizo hincapié GUTIÉRREZ MELLADO al no poder contar con el apoyo suficiente en un ejército opuesto a las reformas ${ }^{78}$.

Estos son, en mi criterio, los principios fundamentales del plan de reformas. Resta todavía por añadir, sin embargo, una cuestión de importancia mayor: el inicio de la reforma de la justicia militar. Aunque no es cuestión que vaya a integrarse en las nuevas Ordenanzas, es preciso hacer al menos una referencia al asunto en este contexto.

Los Pactos de la Moncloa fijaron como un objetivo la reforma de la justicia militar fundamentalmente desde la perspectiva de la reducción de competencia de la jurisdicción militar. Fruto de ello es la promulgación en 1980 de una ley de reforma del Código de Justicia militar que ya viene a desarrollar lo preceptuado en el mismo sentido por la propia Constitución ${ }^{79}$.

Las claves de la reforma son la tecnificación de la jurisdicción militar, que no se alcanza por completo 80 , la reducción de competencias principalmente en la aplicación del fuero personal y la introducción de un recurso de casación de las decisiones del Consejo Supremo de Justicia Militar ante la Sala de lo penal del Tribunal Supremo ${ }^{81}$. Este recurso de casación, por algunos calificado de «increíble" ${ }^{82}$, es el que acaba llevando al ámbito de la jurisdicción civil el conocimiento final del delito de rebelión perpetrado el 23 de febrero de 1981.

La reforma de 1980 es temerosa y tan sólo parcial. El propio legislador ordena la constitución en breve plazo de una Comisión para la reforma legislativa de la justicia militar (disposición final primera) que constituye el anuncio del cambio radical de legalidad que se hará a par-

77 Vid. R. L. Blanco VAldés: La ordenación constitucional de la defensa, cit. pág. 86.

78 Es la interpretación muy coherente de F. AgüERo: Militares, civiles y democracia..., cit., pág. 219.

79 Ley orgánica 9/1980, cit. en nota 26. Vid. Art. 117.5 de la Constitiución.

80 Vid. J. Valenciano Almoyna: La reforma del Código de Justicia militar,... cit., págs. 43 ss.

81 Art. 14 de la Ley orgánica 9/1980. cit., pág. 173. 
tir de 198583. Con todo, cumplió una función importante y vino a constituir un nuevo elemento sustancial de la reforma militar llevada a cabo durante la transición.

Pues bien, dentro del conjunto de líneas por las que discurre la política militar durante este tiempo, las Reales Ordenanzas deben ser concebidas como un elemento más de la reforma. Aunque son, ciertamente, un elemento básico.

Lo son, en primer lugar, por su contenido completo. Las dos perspectivas de la reforma militar están incluidas en él, de tal modo que, al lado de la ley de Órganos superiores de la Defensa nacional de 1978 , vienen a ser la pieza fundamental de la nueva regulación de los elementos básicos de la defensa. Junto con las diversas normas que tienen que ver con el estatuto personal, constituyen un intento completo de regulación de la materia, y el más importante, en la época.

Pero lo son también por la prioridad que reciben en su elaboración. Varias son las razones que, en mi criterio, provocaron la prisa en la elaboración y promulgación de las Ordenanzas. Considero que tuvieron una función primordial: manifestar la intención reformista de GUTIÉRREZ MELLADO y apuntar el camino a seguir en la solución de los diversos problemas. $Y$ de hacerlo con rapidez, pues era necesario ir despejando las dichas soluciones en aspectos tan urgentes como el ejercicio de actividades políticas por los militares en activo.

Hay, desde luego, una razón explícita en la urgencia. La propia Directiva que abre su proceso de elaboración cita como razón poderosa la de salir al paso de los intentos de elaborar un estatuto de la función militar que, a lo que parece, preocupaban a los responsables ${ }^{84}$, especialmente por problemas de sindicación y representatividad que amenazaban con afectar a la disciplina ${ }^{85}$. $Y$ aún hubo, probablemente, otra razón práctica: el intento de ir resolviendo los problemas de adap-

83 Con las leyes 13/1985, del Código penal militar, 12/1985, del Régimen disciplinario de las Fuerzas Armadas, 4/1987 de la Competencia y organización de la Jurisdicción militar, 9/1988, de Planta y organización territorial de la jurisdicción militar y 2/1989, Procesal militar. Textos en Legislación de Defensa nacional, cit., pargf. 18.

84 Vid. F. de Salas López y F. Laguna Sanouirico: Las Reales Ordenanzas en el momento actual...,cit., pág.130.

85 En opinión de A. Albaladejo: El Tratado tercero de las Reales Ordenanzas, cit., pág. 396, "se imponía una ordenanza realista que satisfaciendo a la clase militar con un espíritu clásico, previera al tiempo las futuras reivindicaciones, saliendo al paso de ellas y encauzándolas con arreglo a las normas de la disciplina...". 
tación de las fuerzas armadas en ámbitos que pudieran conducirse mejor y que, a la vez, generasen menos desconfianza entre los componentes de los ejércitos. Algunas explicaciones por parte de los miembros de la comisión redactora entrañan una radical desconfianza hacia una clase política que, sin embargo, estaba dando muestras de una gran amplitud de miras ${ }^{86}$.

Estas circunstancia explican la elaboración de unas Ordenanzas en paralelo a la Constitución. Ciertamente, son coetáneas, luego no puede hablarse de desarrollo constitucional en sentido estricto. De ello eran conscientes los redactores ${ }^{87}$. Pero entraron en vigor con posterioridad al texto constitucional. Este extremo favorece aún hoy el debate sobre la constitucionalidad, toda vez que regulan materias, como las limitaciones de derechos fundamentales, reservadas a ley orgánica por la propia Constitución.

Estimo que puede compartirse la conclusión de quienes sostienen que en tanto no se declare la inconstitucionalidad sobrevenida, las Reales Ordenanzas deben reputarse constitucionales, sin perjuicio de los efectos limitados de la hipotética declaración, puesto que la mayor parte de sus contenidos ya han sido recogidos por otras normas postconstitucionales ${ }^{88}$.

86 Resulta contundente la opinión del autor citado en nota anterior: "Desconocer que en cualquier momento, si no existieran las Reales Ordenanzas, se hubiera podido aprobar un estatuto con un prisma más político que estrictamente profesional es no estar en la realidad. $Y$ estos derechos $y$ deberes podrían fijarse sin una comisión de militares, de mayor o menor valía personal, pero de una íntegra dedicación a su misión y plena responsabilidad..." Y dice candorosamente "Ya de hecho se ha demostrado, con las pocas enmiendas que fueron presentadas al proyecto por parte de congresistas y senadores, que se aceptaba el criterio de que los ejércitos sabían de ordenanzas militares más que cualquier otro experto y por ello el borrador que salió de la comisión...fue aceptado por el Gobierno y, con leves retoques, fue el texto que conoce el lector...", ibid., pág. 398.

87 Lo indica R. Salas Larrazábal: Las Reales Ordenanzas, cit., págs. 129 ss.

88 Véanse las reflexiones de R. Martínez MARTínez: Las Reales Ordenanzas. ¿ ¿Una norma inconstitucional?, en La función militar en el actual ordenamiento constitucional español, ed. M. Ramírez Jiménez, Trotta, Madrid, 1995, págs. 501 ss. También R. Blanco VALDÉs: La ordenación constitucional de la defensa, cit., págs. 9192. A. Gualta considera que al menos algunos de sus contenidos debieran haber sido objeto de una ley orgánica. Vid. Los derechos fundamentales de los militares, cit., pág. 2572. Para J. Jiménez VILlarejo (Principios constitucionales. Derechos y libertades públicas del militar, en La jurisdicción militar, Consejo General del Poder Judicial, 1992, pág. 219) están afectados por la reserva de ley orgánica los contenidos limitativos del ejercicio de los derechos fundamentales y libertades públicas que se contienen en las Ordenanzas. 
Pero, desde luego, no es posible sostener que las Ordenanzas son desarrollo real de la Constitución. Por otra parte, es defendible que se vieran afectadas por la reserva de ley orgánica, pues, siendo formalmente posteriores $y$ tratándose del ejercicio de derechos fundamentales, hay que estar por la menor restricción. Por todo ello, hubiera sido deseable esperar a la promulgación de la norma superior y no situar en paralelo el proceso de elaboración de un texto que, al entrar en vigor con posterioridad, acaba resultando dudosamente constitucional por no contar con rango de ley orgánica.

Con todo, el estado que iba adquiriendo el texto constitucional estaba a la vista de los redactores de las Ordenanzas. Lo demuestran las profusas remisiones que solo pueden referirse, en un cierto anacronismo, a la Constitución en trámite. Lo demuestra también la solución semejante, a veces a la letra, de algunas cuestiones de fondo como, por ejemplo, la coincidencia entre las misiones que el art. $8 .^{\circ}$ de la Constitución asigna a las fuerzas armadas y las del art. $3 .^{\circ}$ de las Reales Ordenanzas ${ }^{89}$. A veces, incluso, se trabajaba con un doble texto en espera de la solución constituciona| ${ }^{90}$.

\section{LA SIGNIFICACIÓN DE LAS REALES ORDENANZAS}

Se han expresado ya las razones que llevaron a la elaboración de las Ordenanzas de 1978 y su importancia como elemento de la reforma. Sería pretencioso para con el propio texto, sin embargo, asignarle la significación básica en el conjunto de la reforma militar. Creo que debe reservarse el papel fundamental en toda la reforma a la Constitución, a cuya promulgación, como se ha dicho, seguramente debían haber esperado.

Las Reales Ordenanzas sí son, no obstante, una pieza importante, la primera entre las de mayor entidad, que en 1978 manifiesta que se va a iniciar con decisión un proceso reformista, y que lo facilita. Una pieza que es capaz de adelantar las soluciones, en mi criterio más adecuadas para el momento de la transición, que se encuentra menos apegada a los planteamientos tradicionales que otras coetáneas, como la ley de Órganos Superiores de la Defensa nacional de 1978, y que sien-

89 Vid. R. Salas Larrazábal: Las Reales Ordenanzas, cit., pág. 133.

90 Noticia de A. Albaladejo: El Tratado tercero de las Reales Ordenanzas, cit., pág. 397. 
ta las bases de una política militar que, progresivamente evolucionada, va a desarrollarse durante la década siguiente.

Para situar con proyección el trabajo de las Ordenanzas y su significación en la evolución de los problemas de la defensa durante los últimos veinte años, me parece conveniente, en primer lugar, calificar el diseño que llevan a cabo sobre el encuadramiento de la organización militar en nuestro sistema.

Los elementos sustanciales de la solución están comprendidos en los artcs. $2 .^{\circ}, 3 .^{\circ}$ y $4 .^{\circ}$. El primero de ellos, por lo que aquí interesa, define la composición de las fuerzas armadas - «constituidas por el Ejército de Tierra, la Armada y el Ejército del Aire»- y las sitúa «bajo el mando supremo del Rey". El art. 3. fundamenta la razón de ser de los ejércitos en "la defensa militar de España" y detalla sus misiones: "garantizar la soberanía e independencia de la Patria, defender la integridad territorial y el ordenamiento cionstitucional». Finalmente, el último supuesto reclama el deber general de defensa y declara a las fuerzas armadas "elemento esencial" de ella.

¿Cómo valorar este planteamiento? Es obvio, por una parte, que las Ordenanzas se integran en esa concepción tradicional de las fuerzas armadas españolas como institución básica del Estado que algunos también reclaman de la Constitución. Por otro lado, mientras que el legislador de la ordenanza tuvo evidentemente a la vista el art. 8 del texto constitucional, que incorpora en su literalidad en el art. $3 .^{\circ}$ (salvo la sustitución de "España» por "Patria»), no se recoge la segunda parte del binomio que la Constitución utiliza91, esto es, el art. 97 que atribuye al Gobierno la dirección «de la Administración civil y militar y la defensa del Estado".

Me parece, por tanto, que las Reales Ordenanzas introducen un planteamiento más cauteloso. Téngase en cuenta que coinciden en el tiempo con la tan citada ley de 1978 (incluso se publican en el mismo $\mathrm{BOE})$ que, como se ha dicho, recoge un diseño que distingue las responsabilidades políticas de las militares. Sin embargo, la circunstancia de que la temática concreta de la organización de la defensa corresponda más bien a esta ley, seguramente suaviza una opinión negativa sobre las Ordenanzas basada en la ausencia de referencias al papel del Gobierno.

91 Mi interpretación se encuentra incluida en los estudios citados en notas 66 y 37 de este trabajo. 
Desde alguna óptica podría entenderse en el mismo sentido la vinculación de las fuerzas armadas a la Corona. No parece, sin embargo, un planteamiento fuera de la ortodoxia. Lo introduce la propia Constitución (art. 62.h) y lo utiliza la legalidad más importante ${ }^{92}$. No es posible, en mi opinión, articular el mando efectivo del Rey sobre los ejércitos en nuestro Derecho, pues sus actos necesitan siempre el refrendo del Gobierno93; las Ordenanzas se integran en esta materia en un sistema definido cuya interpretación, en mi criterio, no deja lugar a dudas.

Lo más notorio, como se ha dicho, es la ausencia de toda referencia al Gobierno en la dirección de la política militar a pesar de las diversas remisiones constitucionales. Quizá no se pudo llegar más allá y los autores se dieron por satisfechos con la aplicación del sentido tradicional de la ordenanza militar. El hecho de que las Ordenanzas no tengan por objeto directamente a la definición de las responsabilidades de la defensa, puede entenderse que las libera de una mayor insistencia en esta cuestión. Y esto resulta, en el fondo, positivo, pues permite su coexistencia tanto con las leyes de 1978 y de Criterios básicos de 1980 cuanto con la reforma de esta última llevada a cabo en 1984. El resto del planteamiento es, sin embargo, muy correcto y se inserta en un diseño que permanece vigente a través de su incorporación a la ley de Criterios básicos de la Defensa nacional en sus redacciones de 1980 y de 1984.

Y así, para las Ordenanzas, las fuerzas armadas, cuya composición es la que la Constitución señala, tienen las misiones que la Constitución les asigna y constituyen el instrumento de defensa militar del Estado dentro del más amplio de la defensa nacional.

Este planteamiento, que en nada se aparta del diseño constitucional, incorpora un elemento novedoso: la defensa militar, es decir, la defensa material o defensa última del Estado a cuya función sujeta la "razón del ser de los ejércitos" (art. 3.\%). Cualquier otra función, a partir de aquí, queda deslegitimada.

Esto supone adelantar una solución que no contempla propiamente el texto constitucional, a saber, la utilización de la pareja de con-

92 Como la Ley de Criterios básicos de1980, la Ley 17/1989, de 19 de julio, reguladora del Régimen del personal militar profesional y su reforma de 1999 que se encuentra en trámite en las Cámaras cuando se escriben estas líneas.

93 Vid., por todos, F. López RAmón: La caracterización jurídica de las fuerzas armadas, cit., págs. 354 ss. 
ceptos defensa nacional - defensa militar. El planteamiento, que quizá permitiría conectar con la idea de sujección incluida en el art. 97 del texto constitucional y que también utiliza, aunque más genéricamente, la ley de Organos superiores de la Defensa nacional de 1978, es la base, a su vez, para definir los conceptos de política de defensa y política militar que hoy se encuentran vigentes a través de su incorporación a la ley de Criterios básicos de 1980.

En conclusión, las Reales Ordenanzas de 1978 se integran, para esta materia, en la línea de organización de las responsabilidades sobre la defensa que se define tempranamente durante la transición. La falta de referencia a las competencias del Gobierno, en el sentido de atribuirle la capacidad de dirección de la defensa, como hace la Constitución, pone de manifiesto una carencia del texto legal. Carencia que, no obstante, no tiene consecuencias por cuanto misión esencial de las fuerzas armadas es la defensa del orden constitucional.

Siendo esto así, no parece arriesgado interpretar que se consideró improcedente avanzar más allá. Sin duda por las dificultades inherentes a la delicada construcción del sistema democrático, se prefirió la gradualidad en la definición del problema. En este sentido, puede sostenerse que las soluciones que más adelante se arbitran son las que entonces se ponen en marcha con cierta timidez. Estas soluciones no sólo no son inconstitucionales, sino que son precisamente las que la Constitución pide en esencia, obviamente desde la ambigüedad que requiere el consenso $y$ con unas Ordenanzas que, por cumplir la función de iniciar el proceso, resultan insuficientes aunque preparan el camino para la solución final.

Hay aún otra cuestión en la que merece la pena detenerse, finalmente, a los efectos de concretar el carácter, naturaleza y función de las Ordenanzas de 1978: El tratamiento de los derechos y deberes, o de deberes y derechos, como dicen las Ordenanzas (Tratado Tercero).

El texto constituye un serio esfuerzo por regular los componentes básicos de la condición del militar. La preocupación fundamental, como se ha dicho, consistía en salir al paso del movimiento hacia la elaboración de un estatuto. La tradición ordenancista española daba pie para introducir una regulación de los derechos y deberes de los militares ${ }^{94}$, pero esta no es la novedad, sino la amplitud con que esta re-

396.

94 Así A. Albaladejo: El Tratado tercero de las Reales Ordenanzas, cit., pág. 
gulación se contempla95. Para ello se utilizan dos elementos que a veces producen un texto descompensado: la regulación de los deberes y derechos del militar (artcs. $168 \mathrm{ss}$.) y la de los deberes $y$ derechos del militar de carrera (artcs. $206 \mathrm{ss}$ ).

Los primeros constituyen el elemento de mayor entidad. Las Ordenanzas introducen una regulación extensa, con otro lenguaje y con carácter más exacto que otras partes del texto ${ }^{96}$.Establecen un elenco que abarca desde derechos y libertades fundamentales (de conciencia y religiosa, de expresión, a la intimidad...) y derechos políticos y ciudadanos, hasta los que llama deberes y derechos de carácter militar (artcs. 186 ss.). Previa la declaración general relativa a la posesión por el militar de todos los derechos civiles y políticos reconocidos en la Constitución (art. 169), se introduce un conjunto de limitaciones al ejercicio de los derechos basado en los elementos que hemos considerado características esenciales de las fuerzas armadas: disciplina y jerarquía y su consecuencia de neutralidad política.

La amplísima utilización de las limitaciones al ejercicio de los derechos se explica, como antes se ha dicho, en razón del intento de evitar el intervencionismo de los militares a través de una profesionalización fundamentada en la disciplina. Ello dio como resultado una legislación muy restrictiva que, basada en medidas de diferente signo, funcionan como un bloque legal muy cohesionado. Así, la Constitución, que sólo permite las restricciones de los derechos para los militares, pero nada más ${ }^{97}$, se combina con un conglomerado de normas anteriores y posteriores a élla, con las Reales Ordenanzas, que constituyen la única regulación sistemática de la materia ${ }^{98}$ y con las leyes penales y disciplinarias que contienen la tipificación de las conductas $y$ las sanciones aplicables ${ }^{99}$.

El resultado es una regulación que, aunque amplía el campo de acción en algunas materias en relación con el sistema anterior, como

95 En opinión de F. de Salas López y F. Laguna Sanquirico: Las Reales Ordenanzas en el momento..., cit.., pág. 129.

96 Es este el lenguaje de la prosa, en contraposición al lenguaje "poético" que hasta aquí venían utilizando las Ordenanzas, dice R. SALAS LARRAZÁbal: Las Reales Ordenanzas, cit., pág. 143.

97 Vid. R. L. BLANCO VALDÉs: La ordenación constitucional de la defensa, cit., págs. $88 \mathrm{ss}$.

98 lbid.

99 Vid. M. Mella MÁrouez: Los grupos de presión en la transición política, cit. pág. 167. 
en la tenencia de órganos de comunicación social o en la libertad de expresión 100 , limita sustancialmente el ejercicio de los derechos ${ }^{101} \mathrm{~V}$, en algunos casos, los deja sin contenido. Tal sucede con el derecho de sufragio pasivo, donde se recogen las tesis del citado Real Decreto-ley de $1977^{102}$, o con la radical limitación del derecho de sindicación, sustituido, según la tesis ampliamente extendida en el ámbito militar, por la teoría del "Estado valedor» incluida ahora legalmente en el art. 181 de las Reales Ordenanzas ${ }^{103}$. Por cierto que el sistema que las Reales Ordenanzas diseñaron para los miembros no profesionales de los ejércitos, consistente en la suspensión temporal de la afiliación, sigue en vigor (art. 182).

Este régimen, en mi criterio, se justificó en su nacimiento por las razones dichas y aún se justifica en buena medida ${ }^{104}$. Las condiciones de ejercicio de algunos de estos derechos han variado para adaptarse a las nuevas circunstancias, como sucede con el derecho de reunión o con el derecho de sufragio pasivo ${ }^{105}$.

La última parte del Tratado Tercero de las Ordenanzas se dedica a lo que impropiamente llama «deberes y derechos del militar de ca-

100 Así, R. L. BLANCO VAloÉs: La ordenación constitucional de la defensa, cit., pág. 93.

101 En opinión de M. Mella Márouez: Los grupos de presión en la transición política, cit., pág. 167. También F. DE Salas López y F. Laguna Sanduirico: Las Reales Ordenanzas en el momento..., cit., pág. 130. R. L. BLANCo VALdÉs la considera, en términos generales, más limitativa que la de otros Estados constitucionales europeos. (Vid. La ordenación constitucional de la defensa, cit., pág. 93), lo cual se explica sin duda por necesidades de la transición.

102 Cuya limitación, en opinión de R. BLANCo VALOÉs, no tiene parangón en Europa. Ibid., págs. 100-101. También R. Pellón RIvero (Actividades políticas y fuerzas armadas, en Jornadas sobre el Titulo Preliminar de la Constitución, cit., pág. 2825) la considera muy restrictiva tomando como referencia el derecho comparado.

103 Vid. F. De Salas López y F. Laguna Sanquirico: Las Reales Ordenanzas en el momento.... cit., pág. 135.

104 Opina igualmente J. Jiménez Villarejo: Principios constitucionales..., cit., págs. 238-239.

105 Ley orgánica 9/1983, de 15 de julio, reguladora del derecho de reunión (BOE de 18 de julio); Ley 17/1989, de 19 de julio, reguladora del Régimen del personal,militar profesional (BOE de 20 de julio), cuya disposición derogatoria 3 . deja sin vigencia finalmente el Real Decreto-ley de 1977 sobre actividades políticas y sindicales. Los militares que deseen ejercer estas actividades pasarán a la situación de excedencia voluntaria regulada en la propia ley. El hecho de que este sistema constituya una limitación al ejercicio de un derecho fundamental y la circunstancia de que la norma no tiene rango de ley orgánica lleva a algún autor a poner en duda su constitucionalidad en este extremo. Vid. J. JIMÉnEZ VILlaReJo: Principios constitucionales..., cit., pág. 221. 
rrera». Más correctamente, se trata aquí de definir algunos aspectos básicos que rigen la carrera militar.

Es un mérito de las Ordenanzas que se sienten algunos principios, pocos ciertamente, pero de importancia, cuales son el acceso a la función militar en condiciones de igualdad (art. 208) o la tenencia del empleo en propiedad (art. 209). También lo es que por primera vez se intente una regulación completa, bien que general, del conjunto de la carrera militar, con normas que regulan desde el inicio de la profesión hasta el retiro, pasando por evaluaciones, profesión, destinos, etc.

Era inevitable, sin embargo, que las Reales Ordenanzas hicieran otra cosa en esta materia que no fuera una regulación muy de principio y general. Más bien habría de sostenerse que no era este el lugar apropiado para tal pretensión. Sea como fuere, aún la ley de Criterios básicos reclama en 1980 una regulación de la carrera militar que con carácter unificador permita superar los defectos de una legislación confusa, dispersa y hasta contradictoria. Y que pide regular también la enseñanza militar, cuestión sobre la que, por cierto, las Ordenanzas pasan de puntillas. Cualquiera de los dos aspectos planteaba, desde luego, dificultades, como lo prueba que estas previsiones no se cumplan hasta 1989.

\section{CONCLUSIÓN}

Las Reales Ordenanzas de 1978 constituyeron un hito importante en la historia de la transición. Fueron una pieza fundamental en la reforma militar.

El proceso de reforma de las Ordenanzas se emprende con urgencia porque se pretende que sirvan de cauce para la acomodación de las fuerzas armadas a las nuevas circunstancias. Cumplen esta función, pero, además, quieren salir al paso de los movimientos a favor de la promulgación de un estatuto militar y lo hacen situando con urgencia en el propio ámbito militar la elaboración de la legalidad que afecta a los militares.

Su fundamental significado es manifestar la decisión de emprender la reforma militar. Sientan las bases del camino a seguir para ponerla en práctica en los dos aspectos de mayor preocupación durante aquel momento, a saber, la incardinación de la defensa en el único poder legítimo del Estado y la profesionalización que evitara el intervencionismo militar. 
Tuvieron, pues, las Ordenanzas un papel de primera magnitud en la reforma. Algunas de las medidas que contienen son, por sí mismas, valiosas, especialmente ciertas referencias constitucionales, e, incluso, audaces, como el tratamiento de la obediencia debida o el rigor que se aplica al ejercicio de los derechos por el militar. Condicionadas por el contexto, iniciaron la reforma posible que, por serlo, contó con algunas carencias, señaladamente la falta de determinación para llegar al fondo en el diseño de la organización de la defensa en la línea constitucional, lo cual, sin embargo, no era propiamente misión suya.

En definitiva, desde la óptica de la oportunidad, las Reales Ordenanzas de 1978 iniciaron positivamente la reforma militar, bien que en un proceso paralelo a la Constitución que, visto hoy, permite achacar una cierta falta de visión de futuro. Cumplieron, también, muy ampliamente su función y apuntaron -cosa nada fácil— el camino de la reforma.

Constituyen, por otra parte, una cierta amalgama desde una perspectiva formal. Algunas carencias provienen de ahí. Mientras que las ausencias detectadas en la regulación de las competencias sobre la defensa pueden quizá justificarse en una norma que pretenda sólo y directamente regular las reglas de comportamiento del militar, su carácter legal y la minuciosidad y contundencia con que se enfrenta a algunos de sus contenidos, no permiten hacerlo.

Finalmente, en cuanto al fondo, considero que las Ordenanzas formularon en general un tratamiento correcto de los problemas fundamentales que a la sazón estaban planteados. Quizá faltó decisión para dar un salto en el tiempo. El contexto de una nada sencilla transición obliga a pronunciarse positivamente por el resultado de la reforma posible que las Reales Ordenanzas diseñaron en el año 1978. 